\title{
BMJ Open Experts' consensus on use of electronic cigarettes: a Delphi survey from Switzerland
}

\author{
Jeremie Blaser, Jacques Cornuz
}

To cite: Blaser J, Cornuz J. Experts' consensus on use of electronic cigarettes: a Delphi survey from Switzerland. BMJ Open 2015;5:e007197. doi:10.1136/bmjopen-2014007197

- Prepublication history and additional material is available. To view please visit the journal (http://dx.doi.org/ 10.1136/bmjopen-2014007197).

Received 26 November 2014 Accepted 3 March 2015

Department of Ambulatory Care and Community Medicine, University of Lausanne, Lausanne, Switzerland

Correspondence to Dr Jeremie Blaser; jeremie.blaser@hospvd.ch

\section{ABSTRACT}

Objectives: In some countries, nicotine-containing electronic cigarettes (e-cigarettes) are considered a consumer product without specific regulations. In others (eg, Switzerland), the sale of e-cigarettes containing nicotine is forbidden, despite the eagerness of many smokers to obtain them. As scientific data about efficacy and long-term safety of these products are scarce, tobacco control experts are divided on how to regulate them. In order to gain consensus among experts to provide recommendations to health authorities, we performed a national consensus study. Setting: We used a Delphi method with electronic questionnaires to bring together the opinion of Swiss experts on e-cigarettes.

Participants: 40 Swiss experts from across the country.

Outcome measures: We measured the degree of consensus between experts on recommendations regarding regulation, sale, use of and general opinion about e-cigarettes containing nicotine. New recommendations and statements were added following the experts' answers and comments.

Results: There was consensus that e-cigarettes containing nicotine should be made available, but only under specific conditions. Sale should be restricted to adults, using quality standards, a maximum level of nicotine and with an accompanying list of authorised ingredients. Advertisement should be restricted and use in public places should be forbidden.

Conclusions: These recommendations encompass three principles: (1) the reality principle, as the product is already on the market; (2) the prevention principle, as e-cigarettes provide an alternative to tobacco for actual smokers, and (3) the precautionary principle, to protect minors and non-smokers, since long-term effects are not yet known. Swiss authorities should design specific regulations to sell nicotine-containing e-cigarettes.

\section{INTRODUCTION}

The use of electronic cigarettes (e-cigarettes) has rapidly increased in recent years, raising worldwide public debate. E-cigarettes include a wide range of devices using aerosol delivery methods and many unanswered questions

\section{Strengths and limitations of this study}

- There is need for health and political authorities to be advised on how to regulate e-cigarettes containing nicotine. As data about long-term safety and health impact of electronic cigarettes (e-cigarettes) are scarce, an expert consensus is an appropriate means to provide recommendations.

- These recommendations can be applied to other countries that do not currently possess specific regulations about nicotine-containing e-cigarettes.

- To the best of our knowledge, this study is the first to use a formal consensus method to propose expert opinion on such a regulation.

- The main limitation of the study is linked to the Delphi method itself, as the results only reflect the opinion of selected experts.

- Another limitation is linked to the rapid evolution of the products and the continuous arrival of new data on safety. Opinions in this report will certainly change as more data become available.

remain. The immediate effects after shortterm use of e-cigarettes have been described, ${ }^{12}$ but there are currently no data about the longterm effects of their use; few studies have investigated the efficacy of e-cigarettes in smoking cessation or reduction.

In Switzerland, currently only e-cigarettes without nicotine may be sold. Citizens can buy e-liquids containing nicotine from abroad or online, albeit a limited volume and for personal use only. ${ }^{3}$ In Europe, the current legislation varies from country to country. A revision of the European directive on tobacco products was adopted by the European Parliament and this came into force in May 2014. The member states have 2 years to adopt the new directive.

Some experts who consider the sale of e-cigarettes as a possible revolution in harm reduction from tobacco, ${ }^{4}$ therefore, advocate that the use of these products should be encouraged and not severely regulated, in order to convince as many smokers as possible to switch to e-cigarettes. Other experts argue 
that e-cigarettes could provide a gateway to nicotine dependence, especially for the young, leading to eventual cigarette smoking. Their use would delay smoking cessation and would renormalise public smoking. ${ }^{5}$ These hypotheses, however, have not been properly tested to date and alternative smoking cessation aids already exist. ${ }^{6}$

Regulation of the sale of e-cigarettes containing nicotine will have a major effect on the development of the product and therefore, on the health of the smoking population. Given the current paucity of scientific evidence to guide health and political authorities, a consensus process is an appropriate way to determine what tobacco control experts agree upon.

The aim of our study was to collect expert recommendations for health authorities regarding the regulation, sale and use of e-cigarettes containing nicotine.

\section{METHODS}

\section{Procedure}

We used the Delphi method to collect experts' opinions. The Delphi method ${ }^{7-9}$ is a validated consensus process, frequently used when evidence is missing. An expert panel is first asked to rate the recommendations. The experts are then provided the results of this first round, allowing them to rerate the recommendations for or against a given consensus. This process can be repeated to help the experts to reach a final consensus.

In the present study, an online questionnaire was submitted to a panel of Swiss experts over the course of four rounds, between September 2013 and January 2014 (figure 1), assessing the extent of their agreement on different statements. The questions were adapted based on the results and comments from the previous round. The research team keeps the original questionnaires, which were available for consultation. As no patient was involved in the study, the Ethics Review Board from the University of Lausanne confirmed that as per the Swiss legislation, no formal ethics approval was necessary.

\section{Expert panel}

The invited experts $(\mathrm{n}=113)$ came from several complementary expert networks: (1) The national programme 'Vivre sans tabac'/'Frei von Tabak' ('Free from Tobacco'), including 50 physicians from all across Switzerland trained to teach other physicians on how to treat tobacco dependence, ${ }^{10}$ (2) the Swiss network 'Hospital Quit Support', a programme intended to bring smoking cessation through consultations in Swiss hospitals, (3) the Swiss university public health network and (4) additional Swiss experts known to the research team for their involvement in tobacco prevention from a clinical or political perspective, as well as those recommended by other experts participating in the study.

\section{Round 1}

The first questionnaire addressed regulations, sale and use of e-cigarettes. Participants had to rate each

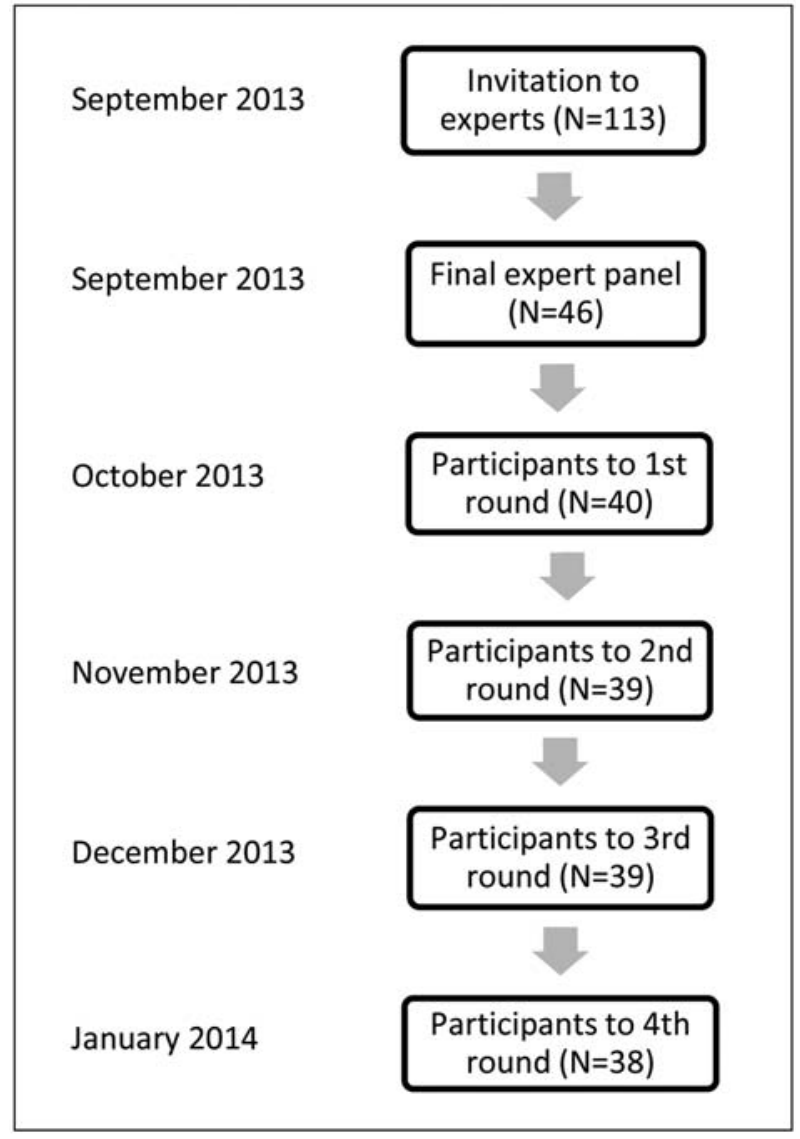

Figure 1 Flow chart of the participation of experts.

recommendation on a scale of $1-10$, where 1 was 'strongly disagree' and 10 was 'strongly agree'. The recommendations that reached a high level of positive agreement (mean score between 8 and 10) were considered as accepted. The recommendations that reached a high level of negative agreement (mean score between 1 and 3) were considered as rejected. The first questionnaire also involved one open-ended question and the possibility to suggest new recommendations. At the same time, participants received documents about e-cigarettes containing nicotine that included three national reports (from UK, ${ }^{11}$ France $^{12}$ and Germany ${ }^{13}$ ), as well as some representative scientific and political information on the topic. ${ }^{3} 46$ 14-18

Example of a recommendation proposed in the first questionnaire:

2.1. Restrictions on sale of nicotine-containing e-cigarettes should be proposed for:

- Non-smokers

- Pregnant women

- Minors

\section{Round 2}

The recommendations that did not reach a significant level of agreement (mean scores between 3.01 and 7.99) were used to create the second questionnaire. They were reformulated following the comments of the experts, 
either to clarify the recommendation or to submit subcategories. We used the answers to the open question, and the experts' suggestions and comments to create new recommendations. In order to facilitate interpretation of results, the experts were asked to rank some of the recommendations in order from most appropriate to least appropriate. The degree of agreement was then determined by the proportion of first choice for each proposition. Cut-offs were set to keep the same intervals used in the other recommendations. The results of the first round from the second questionnaire were made anonymous and provided once again to the experts. The comments and results of the open questions were not transmitted. As for the first round, the recommendations that reached a high level of positive or negative agreement were considered as accepted or rejected, respectively.

\section{Rounds 3 and 4}

The participants had access to the results of previous rounds to rate the recommendations. This process was repeated two more times, in order to reach a consensus for as many recommendations as possible. For the last round, we attached six recent position papers to the questionnaire in order to present further arguments to the participants. ${ }^{19-24}$

\section{RESULTS}

A total of 113 experts were invited to participate in the study (figure 1). Of these, 46 accepted the invite to participate in the first round and 40 filled out the first questionnaire. Only these 40 experts, who replied to the first round, were sent the next questionnaire. The participation rates for rounds 2, 3 and 4 were $97.5 \%, 97.5 \%$ and $95 \%$, respectively.

Of the 40 experts who participated to the first round, $80 \%(\mathrm{n}=32)$ were Swiss experts in tobacco control, $12 \%$ $(n=5)$ were members of the Federal Commission for Tobacco Control, and $8 \%(n=3)$ were proposed by other experts. Thirty-five $(62.5 \%)$ worked mainly as healthcare practitioners (with patients who smoke) and 15 (37.5\%) were educators training other health professionals. Twenty-two of the experts (55\%) worked in the French part of Switzerland, $16(40 \%)$ in the German part and two $(5 \%)$ in the Italian part. Twenty-six (65\%) were males and $14(35 \%)$ were females.

Box 1 shows the recommendations on the regulation of e-cigarettes that reached a high level of agreement by the end of the survey.

Box 2 summarises the recommendations on the sale of e-cigarettes that reached a high level of agreement.

Box 3 shows the recommendations that reached a high level of agreement on the use of e-cigarettes, as well as their general opinion about the product.

\section{DISCUSSION}

The Swiss expert panel agreed that nicotine-containing e-cigarettes should be sold under several restrictions and

\section{Box 1 Regulation}

Item

- Nicotine-containing electronic cigarettes (e-cigarettes) should be sold in Switzerland under specific regulation, different than the current regulations

- E-cigarettes should be considered as either:

- A drug (medication), regulated by Swissmedic

- A new category of products containing nicotine, under specific regulation

- E-cigarettes should not be considered as:

- A tobacco product, regulated like other products containing tobacco (such as cigarettes, pipes and cigars)

- A consumer product, without changing the actual regulation

- If e-cigarettes with nicotine were to be authorised in Switzerland, companies should:

- Respect a list of authorised e-liquid ingredients

- Be on a list of accepted models with specific requirements

- Respect an upper limit of nicotine concentration

- A warning should be stated on the product, especially concerning the potential for addiction and the lack of evidence concerning long-term safety.

- The ingredients of the e-liquid should be stipulated on the product.

without waiting for additional epidemiological or clinical data. The potential of e-cigarettes to be a much safer alternative to conventional cigarettes was the main argument for making them available as soon as possible. Nevertheless, much consideration was given to the lack of data about long-term effects of e-cigarettes on the health of users. Therefore, they agreed on the need for regulations that would protect users by guaranteeing the quality of available e-cigarette products, with an upper limit of authorised nicotine concentration, and adequate information on the ingredients of the e-liquids and their

\section{Box 2 Sale}

Item

- Restrictions on sales should be proposed for minors

- If electronic cigarettes (e-cigarettes) were considered as a medication, restrictions should be proposed for minors and pregnant women

- If nicotine-containing e-cigarettes were to be authorised in Switzerland, they should not be sold by the tobacco industry or related companies

- E-cigarettes should be sold in either:

- Pharmacies

- The same places as tobacco products

- E-cigarettes should not be sold:

- In specialised shops

- Anywhere

A specific tax should be implemented on e-cigarettes

Advertisement should not be allowed:

- In the media

- Targeting minors

- Targeting non-smokers 


\section{Box 3 Use and general opinion}

\section{Item}

- The use of electronic cigarettes (e-cigarettes) should be forbidden in public places

- Health authorities should advise never-smokers not to use e-cigarettes (eg, through a public campaign)

- Health authorities should not encourage smokers to shift to e-cigarettes to help them quit smoking as first-line therapy.

- If e-cigarettes were considered as a medication, they should be either:

- Supplied with a prescription from a doctor

- Supplied on technical advice from medical staff (eg, pharmacies)

- If e-cigarettes become a popular product, nicotine addiction should be seen as a medical and a public health issue

- Research should assess:

- Long-term safety of the product

- Efficacy as a quitting tool

- Psychological and social effects

- Effect of dual consumption: e-cigarettes and tobacco products

- Based on currently available data, e-cigarettes are not dangerous to the health of tobacco smokers

addictive potential. A restrictive list for authorised ingredients of e-liquids should be enacted. In order to control quality and access to the products, nicotinecontaining e-cigarettes should be either considered as a medication or regulated as a new category of products containing nicotine through the enactment of a specific regulation. The first option would require time, as more studies would be required before certain e-cigarettes could be sold as a medical device. A specific regulation, however, could include recommendations proposed by the experts regarding the quality, safety, use and sale of e-cigarettes.

In the present study, the benefit of nicotine-containing e-cigarettes for current tobacco cigarette smokers was largely accepted, although the lack of data on long-term health effects was taken into account. It seemed important to the experts, therefore, to protect minors and current non-smokers by restricting sales of e-cigarettes to adults, as well as by forbidding advertisements in the media, especially those targeting minors and nonsmokers. Consideration was also given to the protection of pregnant women, as we know that nicotine can have negative effects on the fetus. ${ }^{25}$ In order to enforce the proposed recommendations for regulation, e-cigarettes should be sold either in pharmacies or in the same locations as tobacco products. The experts agreed that a tax on e-cigarettes should be implemented, high enough to finance independent research on e-cigarettes, but low enough to keep the product more attractive than conventional cigarettes.

Given the risk of renormalisation of smoking, as well as the currently unknown effects of passive vaping, the experts recommended that e-cigarettes should be banned from closed public places. Health authorities should recommend that non-smokers do not begin the use of e-cigarettes, as the long-term effects on health are not known. As evidence for the efficacy of e-cigarettes as a quitting tool is lacking, they also considered that health professionals should not recommend e-cigarettes as a first-line treatment for quitting smoking conventional cigarettes, but should instead recommend the use of products (nicotine substitutes) and therapies that already have proven efficacy.

Given current data, the experts considered that nicotine-containing e-cigarettes should not be perceived as dangerous to the health of current smokers, as these do have a potential for risk reduction for those who switch from conventional cigarettes. On a societal level, even if e-cigarettes seem to be a much safer way to deliver nicotine than conventional cigarettes, experts agreed that nicotine addiction should be considered as a medical and public health issue, given its addictive potential and unknown long-term effects on health, and not as a moral issue.

Comparing these results to the current legislations in Europe (see online supplementary appendix A), the recommendations of the present study follow the trend to allow e-cigarettes with nicotine. None of the neighbouring countries, however, have specific regulations as proposed in this study to date. The European directive offers a few restrictions that are yet to be applied by the member states, but which does not address many of the concerns identified by the experts of this study.

The main limitation of the study is linked to the Delphi method itself, as the results only reflect the opinion of selected experts. Another limitation is linked to the rapid evolution of the products and the continuous arrival of new data about safety. Opinions in this report will certainly change as more data become available.

\section{CONCLUSION}

This study allowed a panel of experts to reach a consensus on several important questions regarding e-cigarettes containing nicotine, specifically their regulation, sale and use. The study also gathered the general opinion of experts on the nature of e-cigarettes. This should prove useful for health authorities and healthcare professionals for future decision-making on the topic.

These recommendations encompass three principles: the reality principle, as the product is already on the market; the prevention principle, as they provide an alternative to tobacco for actual smokers; and the precautionary principle, as they protect minors and non-smokers while long-term effects remain largely unknown.

Acknowledgements The authors would like to thank Dr Kevin Selby, from the Department of Ambulatory Care and Community Medicine, University of Lausanne for his proofreading and his help with the translating process. They would also thank Dr Isabelle Jacot Sadowski for her great help in the planning process of the study. Finally, they thank all the experts for their participation and useful comments. 
Contributors Both the authors were involved in conceiving and designing the original protocol. JB wrote the first draft of the manuscript with JC. Both the authors contributed to the subsequent and the final drafts. JC is the guarantor of the manuscript.

Funding Department of Ambulatory Care and Community Medicine, University of Lausanne. Partial funding: Swiss Association for Smoking Prevention.

Competing interests None declared.

Provenance and peer review Not commissioned; externally peer reviewed.

Data sharing statement Additional data can be accessed via the Dryad data repository at http://datadryad.org/ with the doi:10.5061/dryad.pd790.

Open Access This is an Open Access article distributed in accordance with the Creative Commons Attribution Non Commercial (CC BY-NC 4.0) license, which permits others to distribute, remix, adapt, build upon this work noncommercially, and license their derivative works on different terms, provided the original work is properly cited and the use is non-commercial. See: http:// creativecommons.org/licenses/by-nc/4.0/

\section{REFERENCES}

1. Farsalinos KE, Polosa R. Safety evaluation and risk assessment of electronic cigarettes as tobacco cigarette substitutes: a systematic review. Ther Adv Drug Saf 2014;5:67-86.

2. Vardavas $\mathrm{Cl}$, Anagnostopoulos $\mathrm{N}$, Kougias $\mathrm{M}$, et al. Short-term pulmonary effects of using an electronic cigarette: impact on respiratory flow resistance, impedance, and exhaled nitric oxide. CHEST 2012:141:1400-6.

3. Charrière R. Lettre d'information $n^{\circ} 146$ : Cigarettes électriques, cigarettes électroniques, cigarettes virtuelles. Berne: OFSP, 2010.

4. Etter JF. Should electronic cigarettes be as freely available as tobacco? Yes. BMJ 2013;346:f3845.

5. Fairchild AL, Bayer R, Colgrove J. The renormalization of smoking? E-cigarettes and the tobacco "endgame". N Engl J Med 2014:370:293-5.

6. Chapman S. Should electronic cigarettes be as freely available as tobacco cigarettes? No. BMJ 2013;346:f3840.

7. Jones J, Hunter D. Consensus methods for medical and health services research. BMJ 1995:311:376-80.

8. Keeney S, Hasson F, McKenna H. Consulting the oracle: ten lessons from using the Delphi technique in nursing research. J Adv Nurs 2006;53:205-12.
9. Hasson F, Keeney S, McKenna $\mathrm{H}$. Research guidelines for the Delphi survey technique. J Adv Nurs 2000;32:1008-15.

10. Jacot-Sadowski I, Humair JP, Cornuz J. "Vivre sans tabac" Programme efficace de formation continue des médecins à la désaccoutumance au tabac. Primary Care 2005;21:485-7.

11. Medicines and Healthcare Products Regulatory Agency. The regulation of Nicotine Containing Products (NCPs). London, United Kingdom: Medicines and Healthcare Products Regulatory Agency, 2013.

12. Dautzenberg B, Delrieu A, Deutsch A, et al. Rapport et avis d'experts sur l'e-cigarette. Office français de prévention du tabagisme. 2013.

13. Pötschke-Langer M. Electronic cigarettes-an overview. Red Series, Tobacco Prevention and Tobacco Control. Heidelberg, Germany: German Cancer Research Center, 2013.

14. Adkison SE, O'Connor RJ, Bansal-Travers M, et al. Electronic nicotine delivery systems: international tobacco control four-country survey. Am J Prev Med 2013;44:207-15.

15. Bullen $\mathrm{C}$, Howe $\mathrm{C}$, Laugesen $\mathrm{M}$, et al. Electronic cigarettes for smoking cessation: a randomised controlled trial. Lancet 2013;382:1629-37.

16. Burstyn I. Peering through the mist: what does the chemistry of contaminants in electronic cigarettes tell us about health risks? Technical report; 2013. http://publichealth.drexel.edu/SiteData/docs/ ms08/f90349264250e603/ms08.pdf (accessed 13 Aug 2013).

17. Caponnetto P, Campagna D, Cibella F, et al. EffiCiency and Safety of an eLectronic cigAreTte (ECLAT) as tobacco cigarettes substitute: a prospective 12-month randomized control design study. PLOS ONE 2013;8:e66317.

18. Commission fédérale pour la prévention du tabagisme. Cigarettes électroniques: Prise de position de la Commission fédérale pour la prévention du tabagisme (CFPT) / août 2012. 2012.

19. Abrams DB. Promise and peril of e-cigarettes: can disruptive technology make cigarettes obsolete? JAMA 2014;311:135-6.

20. Benowitz NL, Goniewicz ML. The regulatory challenge of electronic cigarettes. JAMA 2013;310:685-6.

21. Cobb NK, Cobb CO. Regulatory challenges for refined nicotine products. Lancet Respir Med 2013;1:431-3.

22. Hajek P, Foulds J, Houezec JL, et al. Should e-cigarettes be regulated as a medicinal device? Lancet Respir Med 2013;1:429-31.

23. McKee M. E-cigarettes and the marketing push that surprised everyone. BMJ 2013;347:f5780.

24. Sweanor D, Yach D. Looking for the next breakthrough in tobacco control and health. S Afr Med J 2013;103:810-11.

25. Etter JF. La cigarette électronique: une alternative au tabac? Genève: Suisse, 2012. 